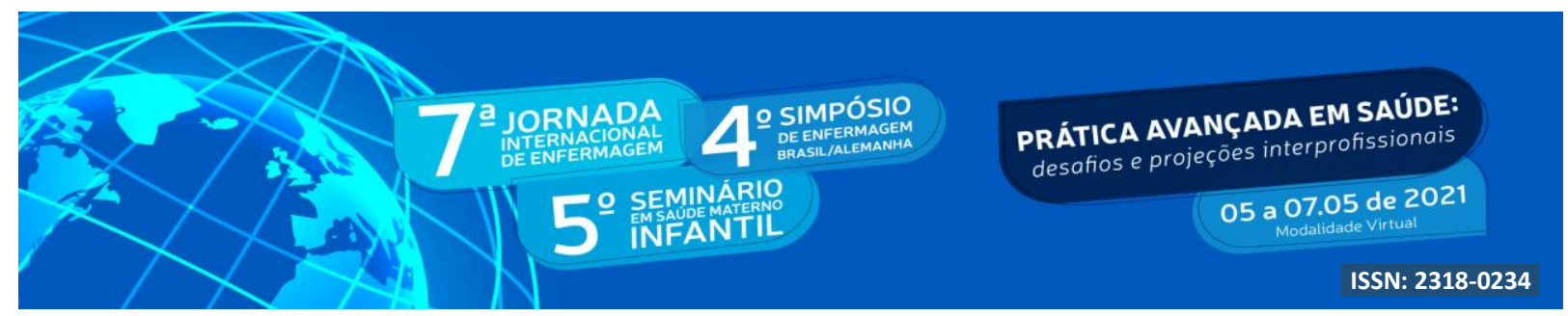

DOI: http://doi.org/10.48195/jie2021-094

\title{
QUAIS EVIDÊNCIAS DEMONSTRAM AS COMPETÊNCIAS NECESSÁRIAS À ATUAÇÃO DA ENFERMAGEM EM URGÊNCIAS E EMERGÊNCIAS? ${ }^{1}$
}

\author{
Luizi Basso de Souza²; Liliane Alves Pereira ${ }^{3}$
}

\begin{abstract}
RESUMO
O presente estudo teve como objetivo identificar o que vem sendo produzido na literatura acerca das competências dos enfermeiros que atuam na área da urgência e emergência. Este artigo trata-se de um estudo do tipo revisão integrativa, com averiguação de artigos presentes na literatura. Os elementos foram coletados por meio das bases de dados Literatura Latino-Americana e do Caribe em Ciências da Saúde (LILACS), BDENF, Medical Literature Analysis and Retrieval Sistem on-line (MEDLINE) e PubMed. A busca foi realizada no mês de dezembro de 2020, totalizando 59 resultados. Após a análise e exclusão dos artigos que não preencheram os critérios de inclusão, utilizou-se um total de 5 artigos para essa revisão. Ademais, ao analisar às competências dos enfermeiros nos serviços de urgência e emergência, este estudo possibilitou a visualização e discussão das evidências das ações na prática, contribuindo para compreensão da importância de sua assistência.
\end{abstract}

Palavras-chave: Enfermagem; Emergências; Competência Profissional.

\begin{abstract}
The present study aimed to identify what has been produced in the literature about the competencies of nurses working in the area of urgency and emergency. This article is an integrative review study, with the investigation of articles present in the literature. The elements were collected through the Latin American and Caribbean Literature in Health Sciences (LILACS), BDENF, Medical Literature Analysis and Retrieval Sistem online (MEDLINE) and PubMed databases. The search was conducted in December 2020, totaling 59 results. After the analysis and exclusion of articles that did not meet the inclusion criteria, a total of 5 articles were used for this review. Moreover, when analyzing the competencies of nurses in the emergency and emergency services, this study allowed the visualization and discussion of the evidence of actions in practice, contributing to an understanding of the importance of their care.
\end{abstract}

Key Words: Nursing; Emergencies; Professional Competence.

\footnotetext{
${ }^{1}$ Revisão de literatura.

${ }^{2}$ Estudante do Curso de Enfermagem. Universidade Franciscana. E-mail: luizibasso20@gmail.com

3 Orientadora Prof ${ }^{\mathrm{a}} \operatorname{Dr}^{\mathrm{a}}$. Docente do Curso de Enfermagem. Universidade Franciscana. E-mail: liliane.pereira@ufn.edu.br
} 


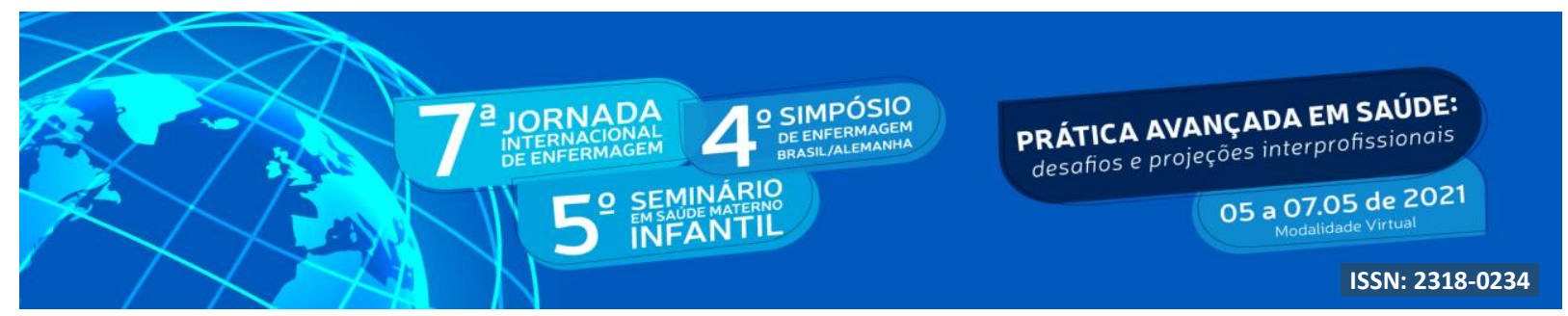

\section{INTRODUÇÃO}

A atuação do enfermeiro no ambiente de emergência requer do profissional a aplicabilidade de competências, como tomada de decisões, liderança, trabalho em equipe, conhecimento científico, ética profissional e um olhar integral ao paciente são competências essenciais para prestar com qualidade a assistência (JESUS, BASANELLI, 2020).

No setor de urgência e emergência em que ocorre momentaneamente o atendimento a usuários graves com risco de vida, a presença do enfermeiro é fundamental e legalmente exigida. Em virtude de este profissional dispor de habilidades e competências para realizar procedimentos necessários ao paciente (FILHO et al, 2016).

Apesar dos termos urgência e emergência serem parecidos, há divergência em suas definições. A Portaria N 354, de 10 de março de 2014, que dispõem sobre as Boas Práticas para Organização e Funcionamento de Serviços de Urgência e Emergência, expõe que a urgência é caracterizada pela ocorrência imprevista de agravo à saúde em que há ou não o risco iminente de morte, onde a pessoa nessa condição demanda de assistência médica imediata. Já a emergência é a constatação de sofrimento intenso ou risco iminente de vida, exigindo, dessa forma, tratamento médico imediato (BRASIL, 2014).

O Manual da Rede de Atenção à Urgência e Emergência (RUE) nas suas diretrizes estabelece o enfermeiro em todos os âmbitos de atendimento, que vai desde o transporte até o atendimento intra-hospitalar, sendo primordial a presença do profissional como parte imprescindível da equipe de atendimento/cuidado (BRASIL, 2013).

Assim o enfermeiro tem avançado cada vez mais em seus espaços de atuação, devido sua prática assistencial e gerencial estar relacionada com evidências técnico-científicas no seu processo de trabalho. Salientando a notoriedade do enfermeiro na esfera da urgência e emergência, onde o mesmo entre a equipe multiprofissional tem o primeiro contato com o paciente (SILVA, INVENÇÃO, 2018).

Com base no exposto anteriormente, o presente estudo tem como questão pesquisa: "Quais evidências demonstram as competências necessárias à atuação da enfermagem em 


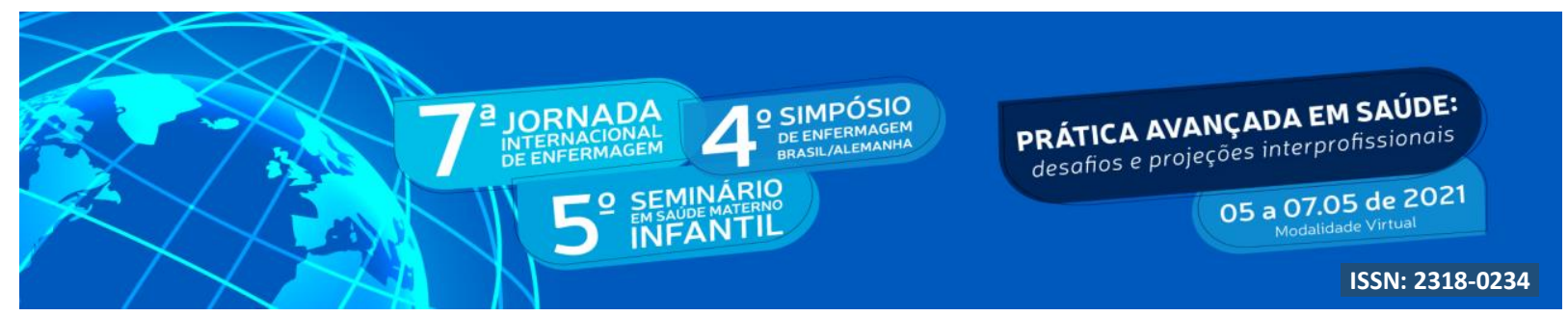

urgências e emergências?',

\section{OBJETIVO}

Identificar o que vem sendo produzido na literatura acerca das competências dos enfermeiros que atuam na área da urgência e emergência.

\section{METODOLOGIA}

Trata-se de um estudo do tipo revisão integrativa, com averiguação de artigos presentes na literatura.

De acordo com Souza; Silva; Carvalho (2010) a revisão integrativa da literatura configura-se como um mecanismo utilizado na área da saúde que proporciona uma prática assistencial fundamentada em conhecimento científico, disponível por meio de pesquisas realizadas sobre diferentes temáticas. Dessa forma a questão pesquisa que norteou a presente revisão foi: "Quais evidências demonstram as competências necessárias à atuação da enfermagem em urgências e emergências?".

Inicialmente foi realizada uma consulta aos Descritores em Ciências da Saúde (DeCS) para definição dos mesmos. Assim, após busca permutada elencou-se como descritores em português e seu respectivo termo em inglês: "Enfermagem/Nurse", "Emergências/Emergencies" e "Competência Profissional/ Professional Competence".

Primeiramente realizou-se uma busca por meio da Biblioteca Virtual em Saúde (BVS) nas bases de dados Literatura Latino-Americana e do Caribe em Ciências da Saúde (LILACS), BDENF e Medical Literature Analysis and Retrieval Sistem on-line (MEDLINE) ocasionando em 43 resultados.

Posteriormente efetuou-se a pesquisa na base de dados PubMed resultando em 16 achados. Foram realizadas as buscas para responder à questão pesquisa com o operador booleano AND.

Os critérios de inclusão definidos para a seleção dos artigos foram: artigos publicados em português e inglês; artigos na íntegra e disponíveis e publicados entre 2016 e 2020. E, 


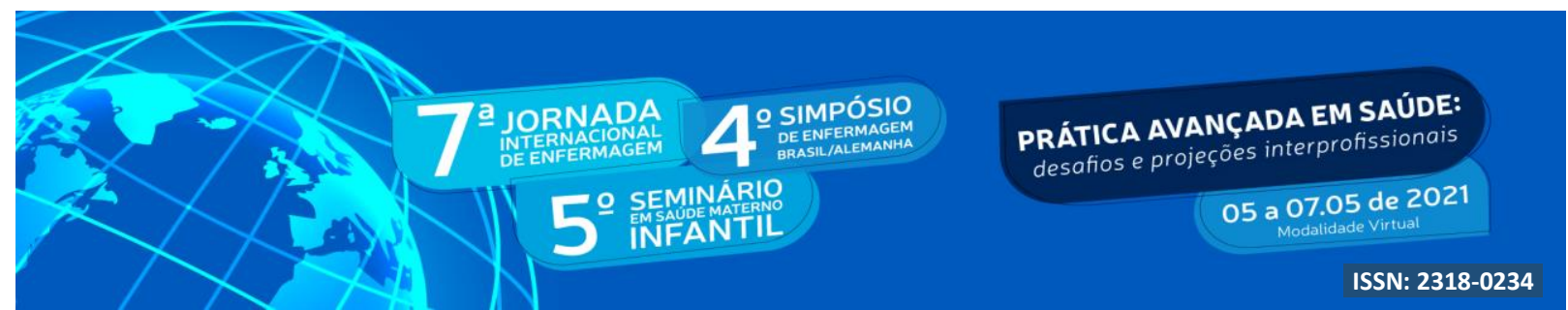

como critérios de exclusão: teses, dissertações, artigos de revisões, resumos de conferências e duplicidades. A busca foi realizada no mês de dezembro de 2020, totalizando 59 resultados.

Posteriormente fez-se a exclusão de 29 artigos que continham o título não condizente com o tema e 13 estudos duplicados. Após a análise das publicações selecionados através dos títulos e resumos excluíram-se 6 que não corresponderam com a questão pesquisa proposta inicialmente e 6 que não preencheram os critérios de inclusão. Assim, utilizou-se um total de 5 artigos para essa revisão.

O procedimento de seleção dos artigos está ilustrado na figura a seguir, o qual se expõe em um diagrama de fluxo da pesquisa (1).

Figura 1. Diagrama da pesquisa

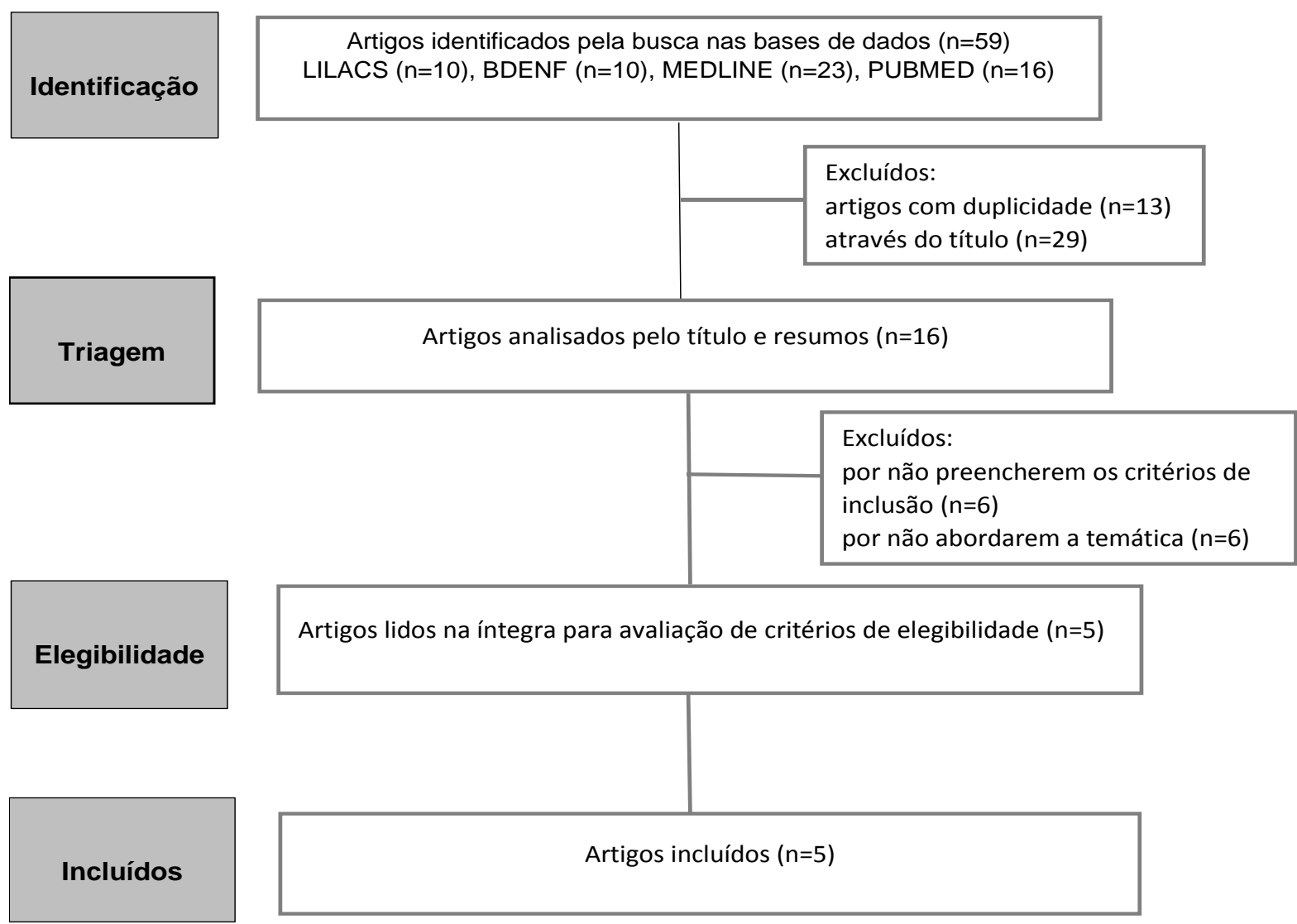




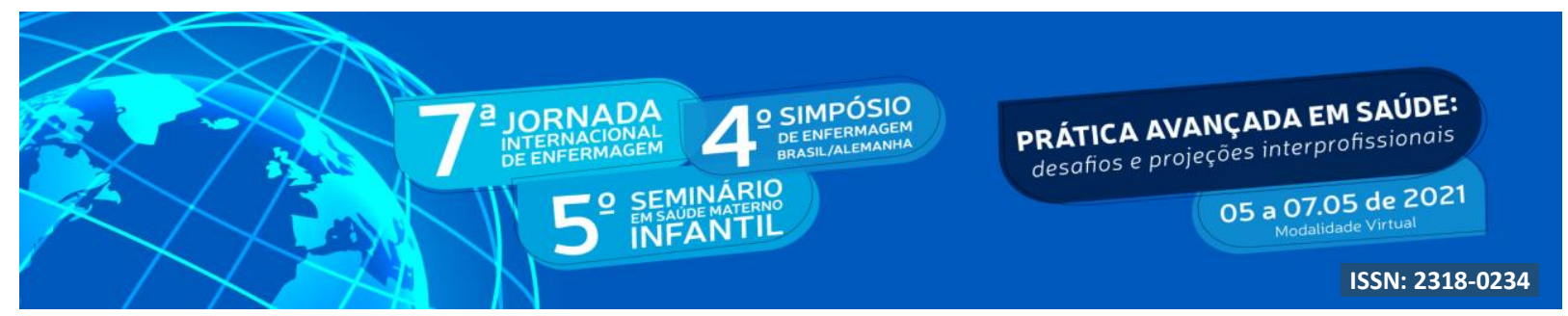

\section{RESULTADOS E DISCUSSÃO}

Os artigos utilizados para essa revisão encontram-se no Quadro 1. Esse quadro está constituído com um código de identificação/referência, o objetivo, metodologia e os principais resultados.

Quadro 1: Identificação dos estudos.

\begin{tabular}{|c|c|c|c|}
\hline $\begin{array}{l}\text { Código de } \\
\text { identificação } \\
\text { /Referência }\end{array}$ & Objetivo & Metodologia & $\begin{array}{l}\text { Principais } \\
\text { resultados }\end{array}$ \\
\hline $\begin{array}{l}\text { (A1) FILHO, } \\
\text { L.A.M.; et al. } \\
\text { Competência legal } \\
\text { do enfermeiro na } \\
\text { urgência/emergên } \\
\text { cia. Enferm. Foco } \\
\text { (Brasília), v.7, n.1, } \\
\text { p.18-23, 2016. }\end{array}$ & $\begin{array}{l}\text { Conhecer quais } \\
\text { procedimentos/aspectos/s } \\
\text { ituações relacionados aos } \\
\text { serviços de } \\
\text { urgência/emergência } \\
\text { foram objeto de } \\
\text { regulamentação por meio } \\
\text { de legislação (resoluções, } \\
\text { pareceres, decisões) pelo } \\
\text { sistema Cofen/Coren }\end{array}$ & $\begin{array}{l}\text { Estudo descritivo exploratório } \\
\text { com abordagem qualitativa e } \\
\text { documental, realizado em } \\
\text { setembro de 2013. A fonte } \\
\text { constituiu-se } \\
\text { Resoluções/Pareceres/Decisões } \\
\text { do Sistema dos Conselhos de } \\
\text { Enfermagem. Foram } \\
\text { selecionadas três resoluções, } 51 \\
\text { pareceres e sete decisões. }\end{array}$ & $\begin{array}{l}\text { Os dados foram } \\
\text { agrupados em três } \\
\text { categorias temáticas } \\
\text { procedimentos que são } \\
\text { e procedimentos que } \\
\text { não são } \\
\text { competência legal do } \\
\text { enfermeiro } \\
\text { urgência/ emergência; } \\
\text { e procedimentos que } \\
\text { são de competência } \\
\text { legal apenas em risco } \\
\text { iminente de morte. }\end{array}$ \\
\hline $\begin{array}{l}\text { (A2) HOLANDA, } \\
\text { F.L.; MARRA, } \\
\text { C.C.; C, I.C.K.O. } \\
\text { Avaliação da } \\
\text { competência } \\
\text { profissional do } \\
\text { enfermeiro em } \\
\text { emergências: } \\
\text { Instrumento criado } \\
\text { e validado. Rev. } \\
\text { bras. enferm, } \\
\text { v.71, n.4, p. 1975- } \\
\text { 1984, 2018. }\end{array}$ & $\begin{array}{lr}\text { Criar Instrumento } & \text { de } \\
\text { Avaliação } & \text { da } \\
\text { Competência } & \\
\text { Profissional } & \text { do } \\
\text { Enfermeiro rror } & \text { em } \\
\text { Emergências, adotando- } \\
\text { se como referencial } \\
\text { teórico-metodológico a } \\
\text { Psicometria para reu } \\
\text { desenvolvimento. }\end{array}$ & $\begin{array}{l}\text { Estudo metodológico realizado } \\
\text { entre } 2013 \text { e } 2016 \text { em } \\
\text { universidade pública, situada na } \\
\text { cidade de São Paulo, Brasil. A } \\
\text { testagem do Instrumento } \\
\text { elaborado nessa investigação foi } \\
\text { realizada em abril de } 2015 \text { com } \\
\text { enfermeiros de um hospital } \\
\text { universitário de grande porte e } \\
\text { alta complexidade Usou-se o } \\
\text { modelo de Pasquali e a } \\
\text { Psicometria como referenciais, } \\
\text { permitindo que fenômenos } \\
\text { subjetivos sejam medidos. }\end{array}$ & $\begin{array}{l}\text { Definir com exatidão } \\
\text { o que o construto } \\
\text { prediz teve extrema } \\
\text { relevância para indicar } \\
\text { como deve ser gerido } \\
\text { o cuidado, bem como } \\
\text { devem ser planejadas } \\
\text { a formação e a } \\
\text { capacitação dos } \\
\text { enfermeiros, inclusive } \\
\text { avaliado } \\
\text { desempenho desse } \\
\text { profissional a fim de } \\
\text { intervir a tempo e a } \\
\text { hora. }\end{array}$ \\
\hline
\end{tabular}




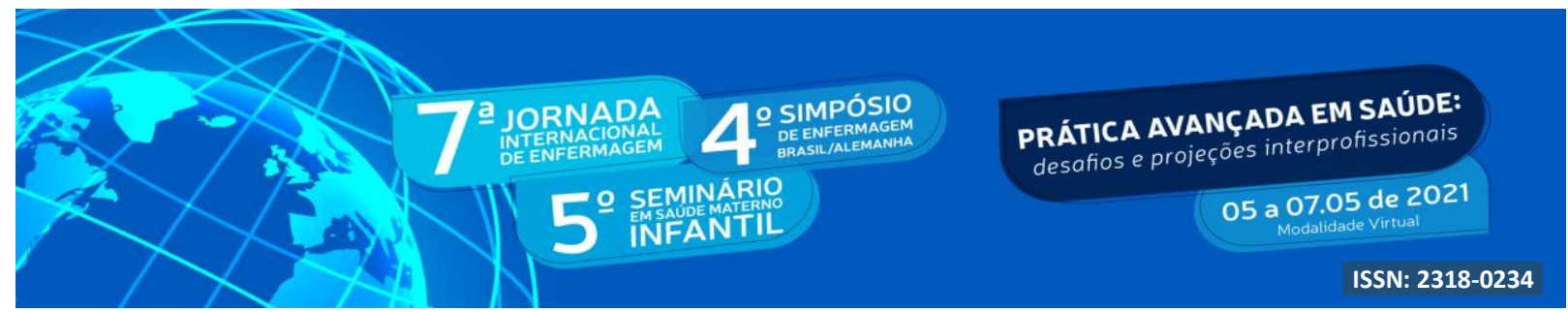

\begin{tabular}{|c|c|c|c|}
\hline 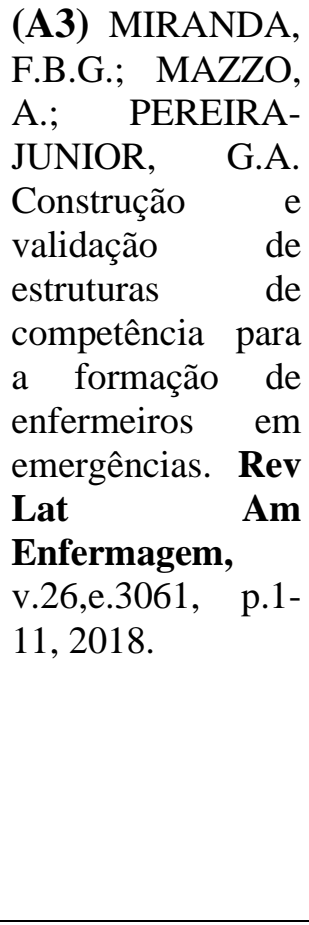 & $\begin{array}{lr}\text { Construir e validar } \\
\text { estruturas } & \text { de } \\
\text { competência a serem } \\
\text { desenvolvidas na } \\
\text { formação de enfermeiros } \\
\text { para o atendimento de } \\
\text { pacientes adultos em } \\
\text { situação de emergência } \\
\text { com foco nas vias aéreas, } \\
\text { na respiração e na } \\
\text { abordagem de circulação. }\end{array}$ & $\begin{array}{l}\text { Trata-se de um estudo descritivo } \\
\text { e metodológico que ocorreu em } \\
\text { três fases: a primeira fase } \\
\text { consistiu em uma revisão da } \\
\text { literatura e uma oficina } \\
\text { envolvendo sete especialistas } \\
\text { para a criação dos quadros de } \\
\text { competência; na segunda fase, } \\
15 \text { especialistas selecionados por } \\
\text { meio da Técnica bola de neve e } \\
\text { técnica de Delfos participaram } \\
\text { da validação facial e de } \\
\text { conteúdo, com análise do } \\
\text { conteúdo das sugestões e cálculo } \\
\text { do Índice de Validação de } \\
\text { Conteúdo para avaliar o acordo } \\
\text { sobre a representatividade de } \\
\text { cada item; na terceira fase, } 13 \\
\text { especialistas participaram do } \\
\text { acordo final do material } \\
\text { apresentado. }\end{array}$ & $\begin{array}{lrr}\text { A maioria } & \text { dos } \\
\text { especialistas } & \text { eram } \\
\text { enfermeiros, } & \text { com } \\
\text { graduação } & \\
\text { experiência } & \\
\text { profissional no } \\
\text { do estudo. } \\
\text { desenvolvidos } \\
\text { validados quadros de } \\
\text { competência para o } \\
\text { treinamento } \\
\text { enfermeiros nas vias } \\
\text { aéreas, abordagem } \\
\text { respiratória } \\
\text { circulação. }\end{array}$ \\
\hline $\begin{array}{l}\text { (A4) } \text { SOARES, } \\
\text { M.I.; } \text { CAMELO, } \\
\text { S.H.; RESCK, } \\
\text { Z.M.; TERRA, } \\
\text { F.S. } \\
\text { Conhecimento } \\
\text { gerencial das } \\
\text { enfermeiras no } \\
\text { ambiente } \\
\text { hospitalar. Rev } \\
\text { Bras Enferm, } \\
\text { v.69, n.4, p.676- } \\
\text { 83, 2016. }\end{array}$ & $\begin{array}{l}\text { Analisar as habilidades } \\
\text { gerenciais dos } \\
\text { enfermeiros no ambiente } \\
\text { hospitalar, sua percepção } \\
\text { de sua própria formação } \\
\text { e a relevância da } \\
\text { formação para sua } \\
\text { prática profissional. }\end{array}$ & 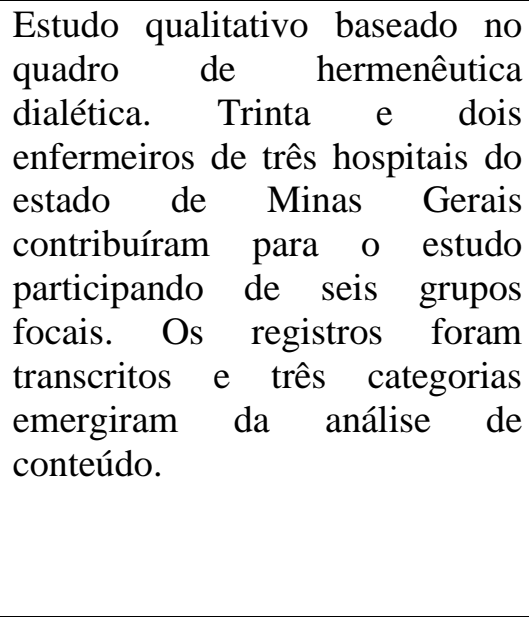 & $\begin{array}{l}\text { Os resultados } \\
\text { evidenciaram as } \\
\text { seguintes habilidades } \\
\text { gerenciais: supervisão, } \\
\text { liderança, tomada de } \\
\text { decisão, planejamento } \\
\text { e organização, bem } \\
\text { como a relevância dos } \\
\text { centros de educação } \\
\text { para sua melhoria e o } \\
\text { desenvolvimento } \\
\text { contínuo } \\
\text { habilidades gerenciais } \\
\text { dos enfermeiros. }\end{array}$ \\
\hline
\end{tabular}




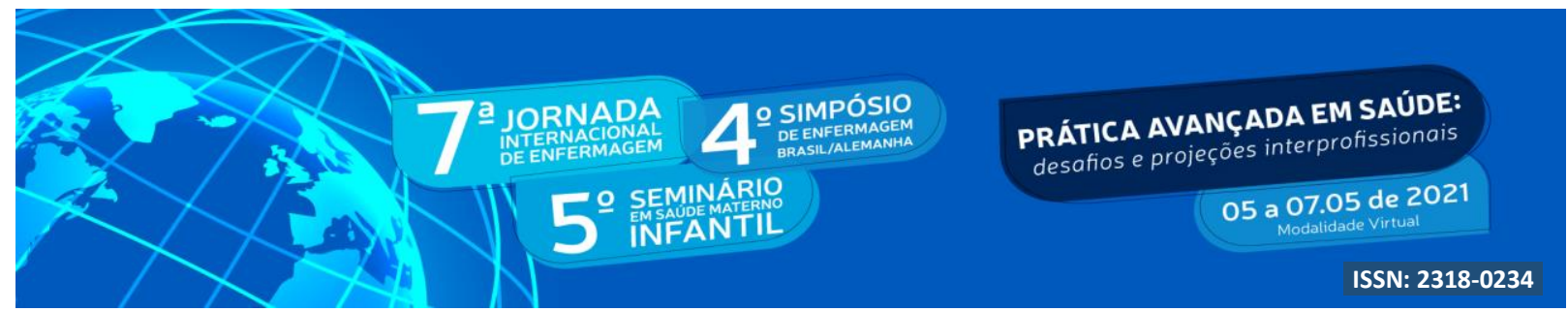

\begin{tabular}{|c|c|c|c|}
\hline $\begin{array}{l}\text { (A5) SOARES, } \\
\text { M.I.; et al. } \\
\text { Estratégias para o } \\
\text { desenvolvimento } \\
\text { da comunicação } \\
\text { em um hospital de } \\
\text { urgência } \\
\text { emergência. Reme: } \\
\text { Rev. Min. } \\
\text { Enferm., v. 24, e. } \\
\text { 1308, p.1-8, 2020. }\end{array}$ & \begin{tabular}{|lr} 
Identificar e & desenvolver \\
estratégias para & o \\
aprimoramento & da \\
competência & da \\
comunicação & em \\
enfermeiros hospitalares.
\end{tabular} & $\begin{array}{l}\text { Estudo exploratório, de } \\
\text { abordagem qualitativa do tipo } \\
\text { pesquisa intervenção. O cenário } \\
\text { foi constituído por uma } \\
\text { instituição hospitalar pública de } \\
\text { ensino, referência no atendimento } \\
\text { em urgências e emergências. A } \\
\text { investigação ocorreu de } \\
\text { novembro de } 2016 \text { a março de } \\
2017 \text { em que participaram } 21 \\
\text { enfermeiros. Utilizou-se a técnica } \\
\text { de grupo operativo para } \\
\text { identificar e desenvolver a } \\
\text { competência da comunicação, } \\
\text { tendo como suporte para a } \\
\text { intervenção um estudo de caso } \\
\text { clínico; posteriormente foram } \\
\text { realizadas entrevistas individuais } \\
\text { para verificar a eficácia da } \\
\text { intervenção aplicada. A análise } \\
\text { dos dados ocorreu por meio de } \\
\text { análise temática indutiva. }\end{array}$ & 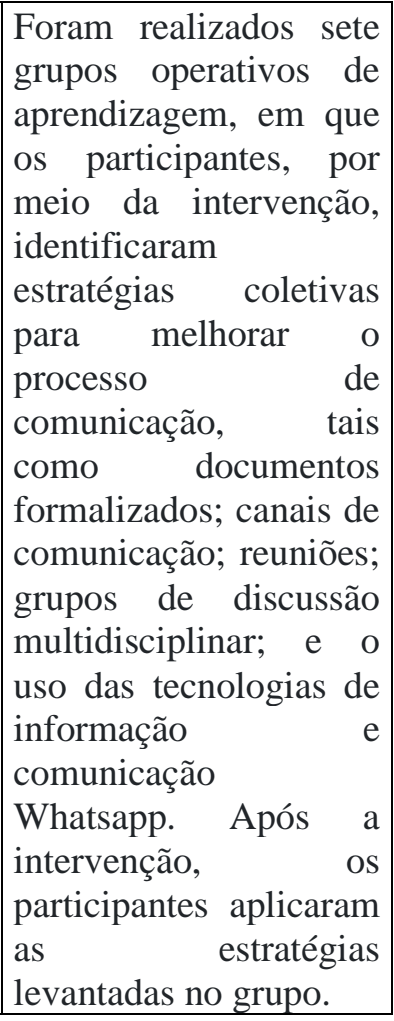 \\
\hline
\end{tabular}

$\mathrm{O}$ artigo (A4) destacou que a liderança do enfermeiro entre a equipe de forma democrática e horizontalizada, além da comunicação e supervisão são competências gerenciais necessárias pelos enfermeiros na condução da equipe. Proporcionando um ambiente de trabalho adequado, através dos vínculos estabelecidos e do diálogo eficiente entre a equipe da enfermagem e os membros da equipe multiprofissional.

O ambiente de urgência e emergência possui um fluxo de atendimento organizado de acordo coma gravidade manifestada pelo paciente, dessa forma, desempenhando o seu papel de enfermeiro, executando sua liderança, apresenta-se como protagonista nas portas dos serviços de urgência (SOARES; BRASILEIRO; SOUZA, 2018).

O estudo (A3) desenvolveu quadros de competência envolvendo conhecimentos, habilidades e atitudes consideradas minimamente necessárias para que os enfermeiros previnem instabilidades e contribuam para o tratamento e recuperação de pacientes adultos durante a abordagem do $\mathrm{ABC}$ com foco nas vias aéreas. Algumas das competências levantadas foram: Conhecimento da anatomia e fisiologia; Identificação dos fatores relacionados às vias aéreas superiores e inferiores; Realização da anamnese e exame físico; 


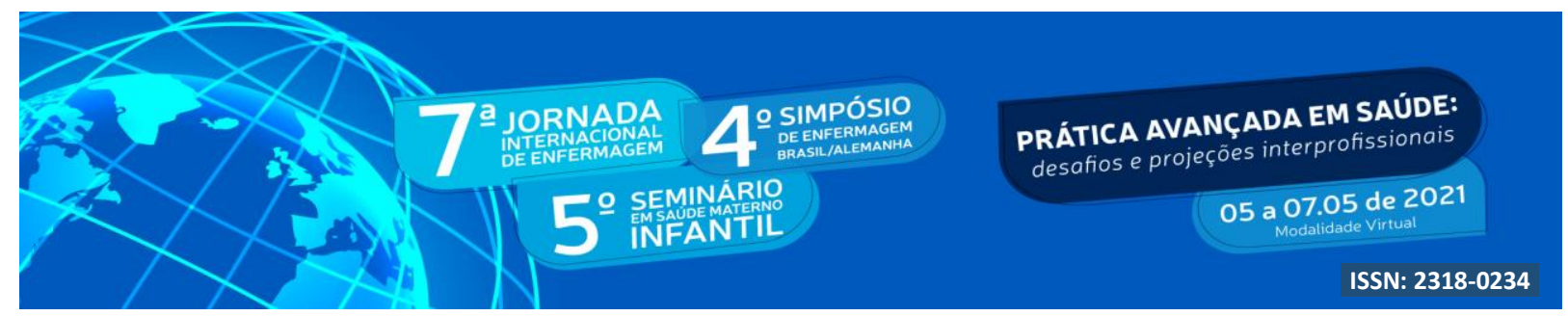

Gerencia a equipe de enfermagem e reconhece e realiza aspiração das vias aéreas.

No artigo (A2) o Instrumento de avalição desenvolvido foi capaz de identificar as ações para prática do enfermeiro em emergências assim foram representadas em 81 itens. A seguir são apresentadas algumas: Supera obstáculos existentes no trabalho com clareza de ideias; Mantém controle emocional ao implantar soluções para os problemas; Atualiza constantemente os conhecimentos em emergências; Percebe as necessidades das pessoas no ambiente em que se encontram; Faz diagnóstico de enfermagem para o cliente conforme referencial teórico adotado na instituição, etc.

Dentre as competências legais do enfermeiro estabelecidas pela pesquisa (A1) ressaltase a Classificação de Risco como privativa do enfermeiro, sendo ele o profissional mais adequado a essa atuação. A prescrição de oximetria contínua, onde os dados obtidos são um parâmetro imprescindível para autonomia do enfermeiro no contexto da urgência/ emergência.

A punção da veia jugular externa frequentemente solicitada ao enfermeiro diante das dificuldades de acesso de uma veia calibrosa em outro sítio de inserção periférica, ressaltando que o profissional deve ter competência técnica e científica. No que se refere à punção arterial para fins de gasometria, geralmente, o enfermeiro adquire competência técnica e científica durante a graduação. A inserção da máscara laríngea e combitubo esofagotraqueal, a desfibrilação com o uso do DEA e manobra vagal, e punção intra-óssea são procedimentos complexos mais voltadas para a atuação dos enfermeiros especialistas (A1).

Silva e Invenção (2018) retratam de competência do profissional enfermeiro na urgência e emergência procedimentos como consulta de enfermagem, administração de medicação e soros intravenosos sob prescrição médica e de sua exclusividade o Acolhimento com Classificação de Risco desenvolvendo assim a escuta do paciente e seu grau de prioridade.

O enfermeiro como gerente da unidade e de sua equipe é o encarregado pelo gerenciamento e planejamento do cuidado prestado, dando-se atenção a todas as tarefas executadas pelos seus pares. Sendo necessário a notificação ao setor administrativo quando essas atividades não garantem a qualidade da assistência (A4, A5).

A atuação nas unidades de urgência e emergência possuem suas próprias especificidades e dinâmicas, onde o cenário de cuidados de alta complexidade são 


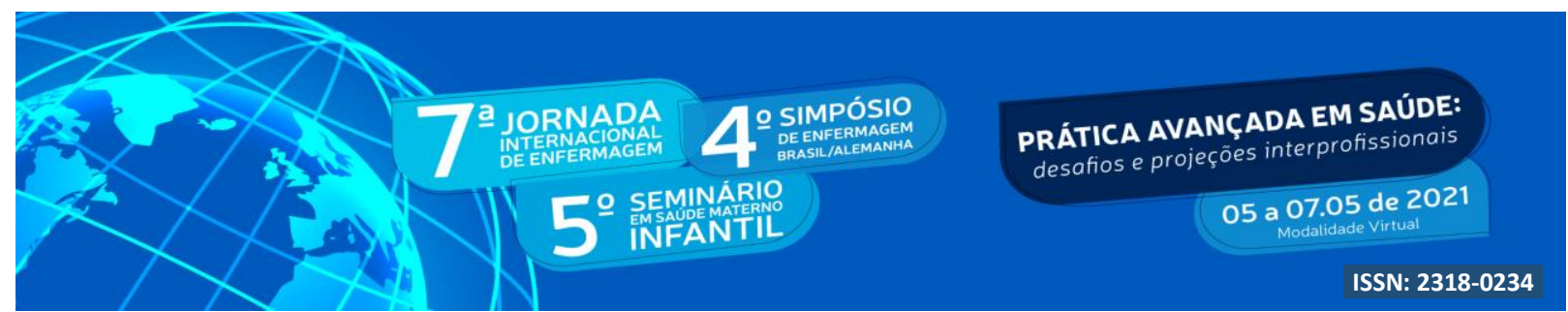

determinantes para a evolução do quadro de saúde-doença do paciente. Exigindo conhecimentos e capacitação específicas, uma vez que o atendimento precisa ser realizado com base técnica e científica (SANTOS et al, 2019).

A análise dos artigos evidenciou que descrever e avaliar as competências profissionais do enfermeiro em emergências foi um grande desafio, pois se trata de uma área nova na enfermagem brasileira com poucos estudos. Dessa forma, a falta de padronização de competências essenciais intercalada com a escassez de ferramentas científicas, em situações críticas, pode colocar tanto o paciente quanto o profissional em risco (A2, A3).

Para transformar a educação e a prática de enfermagem, deve-se encontrar propostas para implementar estratégias educacionais voltadas para o ambiente de prática do profissional como a educação permanente. Destaca-se o planejamento de formação e capacitação dos enfermeiros com o intuito de qualificar o atendimento (A1, A3, A4).

Assim, o estudo (A4) traz que é fundamental às instituições de ensino superior de enfermagem preparar enfermeiros com competência técnica e política, como sujeitos dotados de conhecimento e raciocínio para a prática profissional, capacitando-os para intervir em contextos de incertezas e complexidade.

\section{CONCLUSÃO}

Ao analisar às competências dos enfermeiros nos serviços de urgência e emergência, este estudo possibilitou a visualização e discussão das evidências das ações na prática, contribuindo para compreensão da importância de sua assistência. A atuação do enfermeiro é de notável relevância, sendo o primeiro a entrar em contato com o paciente. A identificação das competências garante maior qualidade na gestão de cuidados.

Estudos futuros nessa área poderão direcionar o enfermeiro de emergência a aprimorar suas ações na assistência prestada. As competências identificadas nos artigos desta revisão necessitam ser aprimoradas nos enfermeiros de emergência, orientando suas condutas para que cada vez mais os profissionais estejam capacitados a prestar de forma crítica e fundamentada um melhor cuidado. Devido ao déficit de pesquisas disponíveis que relatam as competências do enfermeiro nos serviços de urgência e emergência, sugere-se o avanço de 


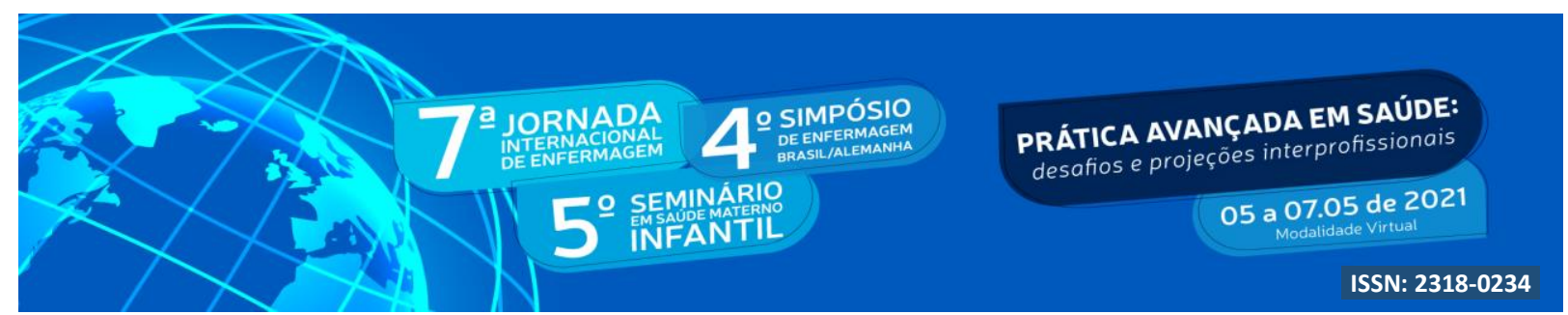

pesquisas na área.

\section{REFERÊNCIAS}

BRASIL. Ministério da Saúde. Manual instrutivo da Rede de Atenção às Urgências e Emergências no Sistema Único de Saúde (SUS). Brasília, 2013.

BRASIL. Ministério da Saúde. Portaria $n^{\circ}$ 354, de 10 de março de 2014. Publica a proposta de Projeto de Resolução "Boas Práticas para Organização e Funcionamento de Serviços de Urgência e Emergência". Brasília, 2014.

FILHO, L. A. M.; et al. Competência legal do enfermeiro na urgência/ emergência. Enfermagem em Foco, v. 7, n. 1, p. 18-23, abr. 2016.

JESUS, J. A.; BALSANELLI, A. P. Competências do enfermeiro em emergência e o produto do cuidar em enfermagem: revisão integrativa. Rev. Rene, v. 21, e43495, 2020.

SANTOS, A. A.; et al. Percepção de enfermeiros emergencistas acerca da atuação e preparo profissional. Rev. Enferm. UFPE online, v. 13, n.5, p.1387-1393, 2019.

SILVA, A. M. S. M.; INVENÇÃO, A. S. A atuação do enfermeiro no atendimento de urgência e emergência. Revista UNILUS Ensino e Pesquisa, v. 15, n. 39, p. 5-13, 2018.

SOARES, A. C. L.; BRASILEIRO, M.; SOUZA, D. G. Acolhimento com classificação de risco: atuação do enfermeiro na urgência e emergência. Revista Recien., v. 8, n. 22, p. 22-33, 2018.

SOUZA, M. T.; SILVA, M. D.; CARVALHO, R. Revisão integrativa: o que é e como fazer. Journal Einstein, v. 8, (1 Pt 1), p. 102-106, 2010. 